\title{
Impaired adipogenesis in insulin-like growth factor binding protein-1 transgenic mice
}

\author{
K Rajkumar, T Modric and L J Murphy \\ Departments of Internal Medicine \& Physiology, University of Manitoba, Winnipeg, R3E OW3 Canada \\ (Requests for offprints should be addressed to L J Murphy)
}

\begin{abstract}
Differentiation of precursor cells into mature fat cells is accompanied by enhanced expression of insulin-like growth factor (IGF)-I and is stimulated by multiple hormones including growth hormone, glucocorticoids, IGF-I and insulin. We used transgenic mice that overexpress insulin-like growth factor binding protein-1 to investigate the role of IGF-I in the accumulation of fat tissue. In response to a sucrose-enriched diet, transgenic mice gained significantly less body weight and the epididymal fat mass was significantly reduced compared with wild-type mice. The increase in adipocyte size was also significantly reduced in transgenic mice compared with
\end{abstract}

wild-type mice. Fewer colonies were generated from adipose tissue from transgenic mice and the mitogenic response of these cells to IGF-I was significantly reduced compared with those from wild-type mice. Induction of glycerol-3-phosphate dehydrogenase, a measure of adipocyte differentiation, by IGF-I but not insulin, was reduced in preadipocytes from transgenic mice. These data indicate that IGF-I has a critical role in the proliferation of adipocyte precursors, the differentiation of preadipocytes and the development of obesity in response to calorie excess.

Journal of Endocrinology (1999) 162, 457-465

\section{Introduction}

The accumulation of adipose tissue involves commitment of stem cells to differentiate into adipoblasts, which undergo further differentiation into preadipocytes, young adipocytes and, eventually, mature adipocytes (Zezulak \& Green 1986, Nougues et al. 1993, Doglio et al. 1987). Growth hormone has been shown to induce both differentiation of precursor cells and expression of insulin-like growth factor (IGF)-I (Doglio et al. 1987, Zezulak \& Green 1986), whereas clonal expansion of the committed adipocyte precursors appears to be under control of autocrine or paracrine actions of IGF-I (Gaskins et al. 1990). However, there is, as yet, no direct in vivo proof that IGF-I expression is required for adipogenesis. Indeed, in primary cultures of preadipocytes (Deslex et al. 1987), insulin appears to be more potent than IGF-I in inducing differentiation, whereas in 3T3-L1 cells, IGF-I is more potent than insulin (Smith et al. 1988). Furthermore, many in vitro studies using either primary cultures or preadipocyte cell lines have found that a variety of factors, other than IGF-I and insulin, can also induce preadipocyte differentiation (Deslex et al. 1987).

The IGF binding proteins (IGFBPs) are present in the serum, other biological fluids and tissue extracts. These proteins bind the IGFs (-I and -II) with affinities comparable to those of the IGF-I receptor (Rechler 1993). The IGFBPs limit the bioavailability of the IGFs and can inhibit the actions of the IGFs in a variety of in vitro bioassays. We have previously reported the generation of transgenic mice that overexpress IGFBP-1 from very early in embryogensis (Rajkumar et al. 1995, Huang et al. 1996). These mice have phenotypic manifestations consistent with partial inhibition of IGF action.

In addition to modest growth retardation at birth, these transgenic mice grow less rapidly in the post-natal period than wild-type mice (Rajkumar et al. 1995). They also demonstrate hyperglycemia and impaired glucose tolerance (Rajkumar et al. 1995, 1996b). Although the IGFBP-1 transgenic mice are initially hyperinsulinemic, their serum insulin concentrations and pancreatic insulin content decline with age (Rajkumar et al. 1996b). However, unlike other rodent models of type 2 diabetes, these mice were observed to have reduced adipose tissue. Here, we have utilized sucrose-induced obesity to investigate the role of IGF-I in adipogenesis in transgenic mice in which partial inhibition of IGF-I action is achieved by over-expression of IGFBP-1.

\section{Materials and Methods}

Animal studies

Homozygous transgenic mice of the 277A strain were used for all experiments. These transgenic mice were generated 
using a rat genomic fragment containing the entire coding region of the IGFBP-1 gene inserted downstream of the mouse phosphoglycerate kinase promoter (Rajkumar et al. 1995). Wild-type mice of the same genetic background were generated from non-transgenic offspring of founder mice and bred in a fashion similar to that for the transgenic mice. The serum concentrations of IGFBP-1 in adult transgenic mice were $11.5 \pm 1.3 \mathrm{ng} / \mathrm{ml}$, whereas those in the wild-type mice were less than $0 \cdot 1 \mathrm{ng} / \mathrm{ml}$; serum total IGF-I and growth hormone concentrations are similar in adult transgenic and wild-type mice (Rajkumar et al. 1995 and unpublished observations). All studies were performed in male mice between 55-60 days of age. In sucrose feeding experiments, transgenic and wild-type mice were allowed access to water supplemented with $10 \%$ sucrose ad libitum for a period of 2 months. Animal experimentation was performed in accordance with protocols approved by the Animal Care Committee of the Faculty of Medicine, University of Manitoba.

\section{Isolation of adipocyte precursors}

Epididymal fat pads were removed under sterile conditions and transferred to ice-cold DMEM/F12 medium containing penicillin, streptomycin and fungizone (Gibco Life Sciences, Burlington Ontario, Canada). Stromal vascular cells were obtained by collagenase digestion of minced tissue. The digestion was performed at $37^{\circ} \mathrm{C}$ with controlled agitation for $60 \mathrm{~min}$ in DMEM/F12 containing $2 \mathrm{mg} / \mathrm{ml}$ collagenase (Type II) and $20 \mathrm{mg} / \mathrm{ml}$ bovine serum albumin. Unless otherwise specified, all reagents were obtained from Sigma Chemical Co., St Louis, MO, USA. After digestion, the tissue was filtered through a screen to remove undigested tissue. The filtrate was centrifuged at $600 \mathrm{~g}$ for $5 \mathrm{~min}$ to sediment stromal cells and preadipocytes and the floating mature adipocyte cell layer was aspirated. The pelleted cells, consisting of adipocyte precursors including preadipocytes and other stromal cells, were washed three times in DMEM/F12 and eventually suspended in this medium.

\section{Proliferation studies}

The cells, isolated as described above, were cultured at a density of $100-200 \mathrm{cell} / \mathrm{cm}^{2}$ in $35 \mathrm{~mm}$ culture dishes in DMEM/F12 supplemented with antibiotics and 10\% fetal bovine serum. The next day, the cultures were washed twice with serum-free DMEM/F12 and new serum-free medium containing $2 \mathrm{~nm}$ tri-iodothyronine and $10 \mu \mathrm{g} / \mathrm{ml}$ transferin. After a further $24 \mathrm{~h}$, serum-free medium containing varying amounts of IGF-I (Upstate Biotechnology Inc., Lake Placid, NY, USA) or bovine insulin was added. At this time, ${ }^{3} \mathrm{H}$-methyl thymidine (Dupont Canada Inc., Mississauga, Ontario, Canada) at a final concentration of $5 \mu \mathrm{Ci} / \mathrm{ml}$ was added to each dish. In some experiments, human recombinant IGFBP-1 (Upstate Biotechnology
Inc) was also added. The incubation was terminated $24 \mathrm{~h}$ later by washing the monolayer twice with PBS and then with ice-cold 10\% trichloroacetic acid. The monolayers were subsequently washed with $70 \%$ ethanol and solubilized with $0 \cdot 1 \mathrm{~N} \mathrm{NaOH}$. After neutralization with $\mathrm{HCl}$, radioactivity was determined in an aliquot using a Wallac Microbeta liquid scintillation counter. The effects of insulin and IGF-I were expressed as a percentages compared with the untreated control dishes.

\section{Glycerol-3-phosphate dehydrogenase (GPDH) activity}

Cultures containing adipocyte precursors were grown in $100 \mathrm{mM}$ culture dishes in DMEM/F12 medium containing $10 \%$ fetal calf serum (FCS). After 4-5 days, confluence was reached and the monolayers were washed with serum-free medium and cultured for a further 6 days in DMEM/F12 containing 5\% charcoal-treated serum and $100 \mathrm{nM}$ hydrocortisone. Some cultures were exposed to either $10 \mathrm{nM}$ bovine insulin or IGF-I. Media and hormones were replenished every 2 days. To all cultures, 1-methyl-3-isobutylxanthine was added for the first 2 days, at a final concentration of $0.5 \mathrm{mM}$. After 6 days, the cultures were washed with PBS and the cells removed with a rubber spatula and suspended in $50 \mathrm{mM}$ Tris, $\mathrm{pH} 7 \cdot 4$, containing $1 \mathrm{mM}$ EDTA and $1 \mathrm{mM} \beta$ mercaptoethanol. The cell suspension was sonicated and centrifuged at $10000 \boldsymbol{g}$ for $30 \mathrm{~min}$. GPDH activity was measured in the supernatant as described previously (Wise \& Green 1979).

\section{Accumulation of intracellular fat}

Cultures containing adipocyte precursors were isolated and grown as described above. At $72 \mathrm{~h}$ after plating, the cell monolayer was washed with serum-free medium and cultures were grown for a further 6 days in medium containing 1\% charcoal-treated FCS, 1\% charcoal-treated FCS plus $100 \mathrm{nM}$ IGF-1 or 10\% charcoal-treated FCS. Medium was replenished on alternate days. The monolayers were stained with Oil-red O, examined microscopically and the percentage of cell containing fat droplets was determined.

\section{Colony formation}

The cells derived from the equivalent of $25 \mathrm{mg}$ of epididymal fat were plated into $35 \mathrm{~mm}$ tissue culture dishes and grown in DMEM/F12 medium supplemented with $10 \%$ FCS. Non-adherent cells were removed after $24 \mathrm{~h}$ and the medium was replaced. After a further $72 \mathrm{~h}$, the cultures were stained with crystal violet and the number of colonies containing more than 20 cells were determined. The average area of the colonies from transgenic and wild-type mice were determined by measuring two diameters of 10 randomly selected colonies. 
Table 1 Effects of sucrose feeding in wild-type and transgenic mice

\begin{tabular}{|c|c|c|c|c|}
\hline & \multicolumn{2}{|l|}{ Wild-type } & \multicolumn{2}{|l|}{ Transgenic } \\
\hline & Control & Sucrose & Control & Sucrose \\
\hline $\begin{array}{l}\text { Fasting blood } \\
\text { glucose }(\mathrm{mmol} / \mathrm{l})\end{array}$ & N.D. & $3 \cdot 07 \pm 0 \cdot 21$ & N.D. & $4.56 \pm 0.69 \dagger$ \\
\hline $\begin{array}{l}\text { Random blood } \\
\text { glucose }(\mathrm{mmol} / \mathrm{l})\end{array}$ & $7 \cdot 06 \pm 0 \cdot 27$ & $7 \cdot 00 \pm 0 \cdot 44$ & $7 \cdot 21 \pm 0 \cdot 16$ & $8 \cdot 10 \pm 0 \cdot 23^{* *} \dagger$ \\
\hline $\begin{array}{l}\text { Food consumption } \\
\text { (g/day per } 100 \text { g body wt) }\end{array}$ & $15 \cdot 00 \pm 0 \cdot 35$ & $9 \cdot 54 \pm 0 \cdot 49^{* *}$ & $15 \cdot 33 \pm 0 \cdot 57$ & $10 \cdot 30 \pm 0 \cdot 24^{* *}$ \\
\hline $\begin{array}{l}\text { Total energy } \\
\text { consumption } \\
\text { (kcal/day per } 100 \text { g body wt) }\end{array}$ & $52 \cdot 52 \pm 1 \cdot 20$ & $59 \cdot 93 \pm 2 \cdot 9^{*}$ & $53 \cdot 64 \pm 1.99$ & $58 \cdot 18 \pm 1 \cdot 43^{*}$ \\
\hline Serum leptin & $1 \cdot 39 \pm 0 \cdot 23$ & $10 \cdot 92 \pm 2 \cdot 74^{* *}$ & $2 \cdot 00 \pm 0 \cdot 37$ & $5 \cdot 18 \pm 0.53^{*} \dagger$ \\
\hline
\end{tabular}

N.D. not determined. ${ }^{*} P<0 \cdot 05,{ }^{*} P<0 \cdot 01$ compared with control; $+P<0 \cdot 05$ compared with wild-type mice.

\section{Morphometric analysis}

Epididymal fat was fixed in 10\% buffered formalin. Tissue from four to six mice per group were utilized. The tissue was embedded in paraffin and serial sections $6 \mu \mathrm{m}$ thick were cut and stained with hematoxylin and eosin. Sections were examined by light microscopy. Photomicrographs were scanned using an Abaton Scan 300/Color scanner. The digitized images were analyzed on a PC computer using the UTHSCSA ImageTool program (developed at the University of Texas Health Science Center at San Antonio, Texas and available from the Internet by anonymous FTP from maxrad6.uthscsa.edu). Using this software, the cross-sectional areas of about 100 adipocytes per section were determined.

\section{RNA extraction and Northern blot analysis}

RNA was extracted from culture cells using the singlestep method (Chomczynski \& Sacchi 1987). For Northern blot analysis, $20 \mu \mathrm{g}$ total RNA was denatured in 50\% formamide and $2 \cdot 2 \mathrm{M}$ formaldehyde, size-separated by electrophoresis on $1 \%$ agarose gels containing $2 \cdot 2 \mathrm{M}$ formaldehyde and then blotted onto nitrocellulose. Filters were hybridized with rat IGFBP-1 and glyceraldehyde phosphate dehydrogenase cDNA probes (Murphy et al. 1990, Rajkumar et al. 1995). Prehybridization and hybridization were performed at $42{ }^{\circ} \mathrm{C}$ in the presence of $50 \%$ deionized formamide as described previously (Murphy et al. 1990). Filters were exposed to Kodak XAR film at $-70{ }^{\circ} \mathrm{C}$ with an intensifying screen.

\section{Blood glucose and serum leptin determinations}

Glucose was measured in whole blood obtained from the retro-orbital sinus of anesthetized mice using a YSI 2300 glucose analyzer (Yellow Springs, OH, USA). Mouse leptin was measured by radioimmunoassay using reagents obtained from Linco Research Inc., St Louis, MO, USA.

\section{Statistical analysis}

All data are presented as the mean \pm s.E.M. Significant differences between transgenic and wild-type mice were determined for various parameters using either Student's $t$-test or an analysis of variance using the PC-SAS statistical package. Least-squares analysis of variance was performed using the General Linear Models analysis. A two-by-two design consisting of mouse type (wild-type or transgenic) and treatment (sucrose or control) was used.

\section{Results}

The differences in blood glucose, food consumption and water consumption over the 1 month of sucrose feeding are shown in Table 1 . We have previously reported that fasting blood glucose concentrations are significantly higher in transgenic versus wild-type mice (Rajkumar et al. 1995). There was also a significant difference in the random blood glucose concentrations in sucrose-fed mice, with transgenic mice having 16\% higher blood glucose values. Because of the difference in size between the transgenic and wild-type mice, food and water consumption have been normalized for body weight. The addition of sucrose to drinking water markedly increased water consumption in both transgenic and wild-type mice; food consumption was reduced as a consequence. However, total energy consumption was significantly increased in both transgenic and wild-type mice by the addition of sucrose to drinking water. There was no significant difference between transgenic and wild-type mice in terms of energy consumption in either control or sucrose-fed mice. 

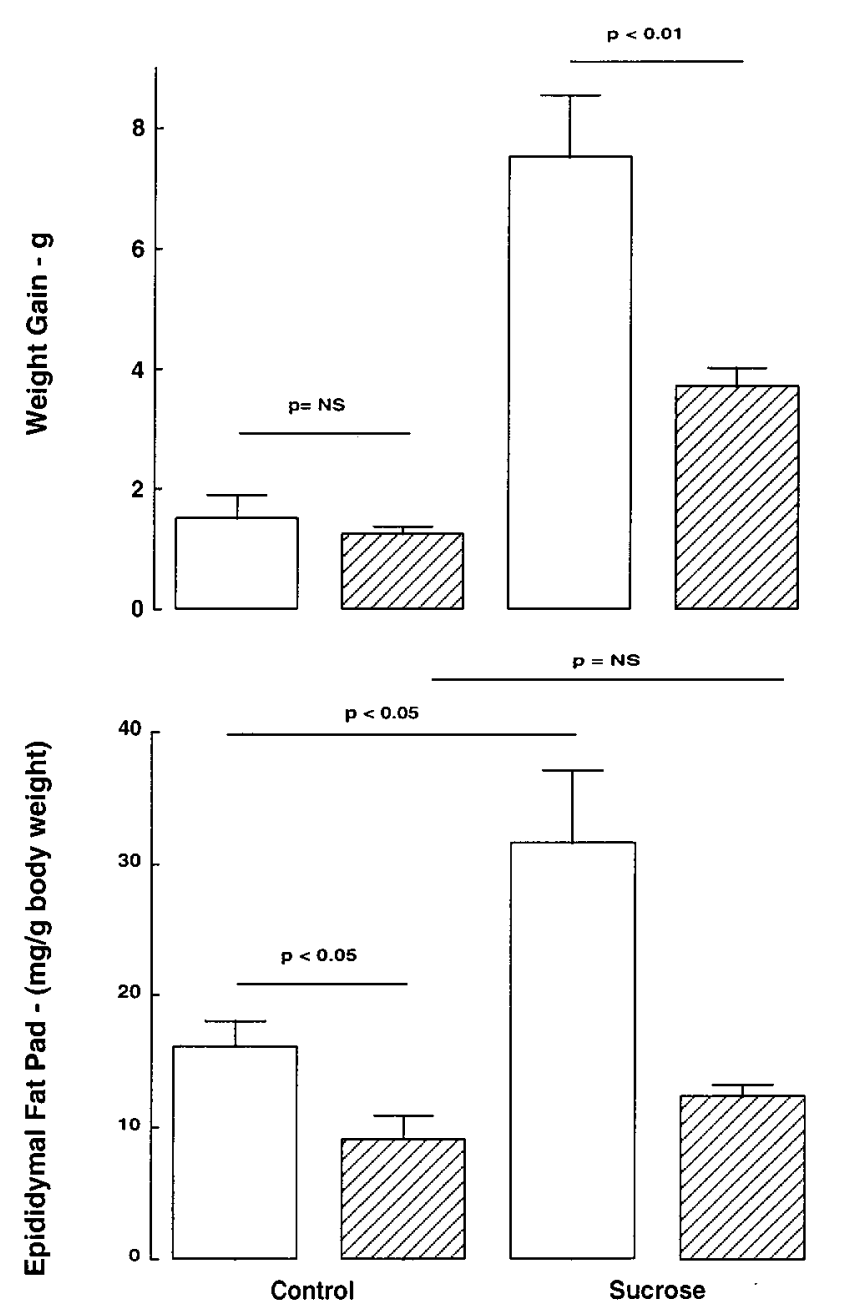

Figure 1 Body weight gain and the relative weight of the epididymal fat pad in control and sucrose-fed wild-type mice (open columns) and transgenic mice (cross-hatched columns). The absolute weight gain over the 2-month period in the two groups of mice is shown in the top panel. In the lower panel, the relative weight of the epididymal fat pad expressed per gram body weight is shown. The data represent the means \pm S.E.M. for five to eight mice per treatment group. The significant differences between groups are indicated.

After 2 months of sucrose feeding, the wild-type mice gained almost twice as much body weight as the sucrosefed transgenic mice and five time more weight than the non-sucrose-fed wild-type mice (Fig. 1). Over the same time period, control wild-type and transgenic mice fed normal rodent chow gained a similar amount of weight. In sucrose-fed wild-type mice there was a doubling in the relative weight of the epididymal fat pad (Fig. 1), whereas there was no significant increase in the relative weight of the epididymal fat pad from transgenic mice. Although not quantified, other fat deposits also appeared to be increased in sucrose-fed wild-type mice, but were not noticeably

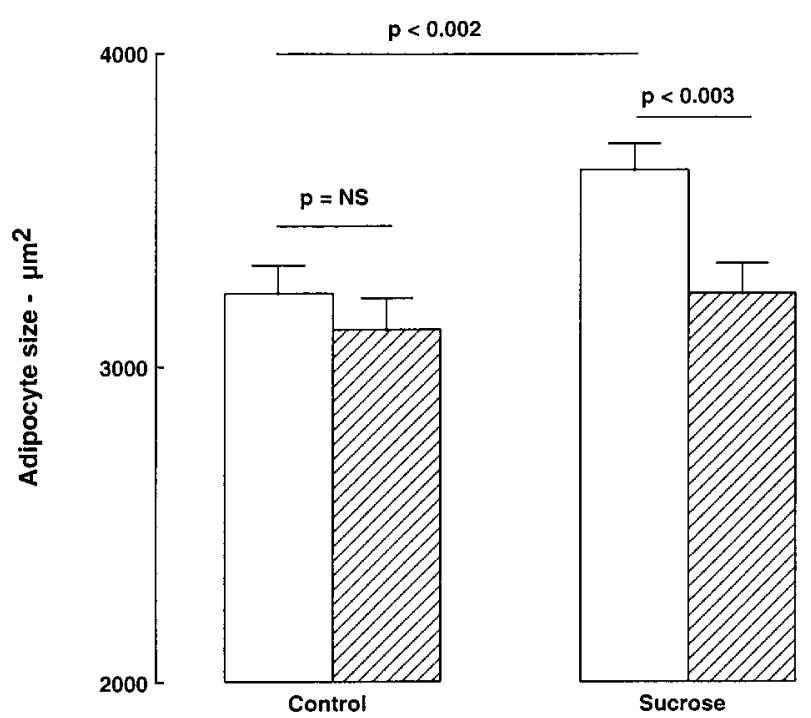

Figure 2 Adipocyte size in transgenic mice (cross-hatched columns) and wild-type mice (open columns). The statistical difference between the various groups was determined by analysis of variance.

increased in sucrose-fed transgenic mice. Serum leptin concentrations, which are believed to correlate with total body adipose mass, were measured in blood sucrose and non-sucrose-fed mice. The leptin concentrations increased approximately twofold in transgenic mice fed with $10 \%$ sucrose, whereas they increased approximately sixfold in the wild-type mice (Table 1).

Adipocyte size was slightly reduced in transgenic mice compared with wild-type mice under basal control conditions: $3119 \pm 103$ compared with $3239 \pm 89 \mu \mathrm{m}^{2}$; however, this difference did not achieve statistical significance (Fig. 2). In wild-type, but not transgenic mice, adipocyte size was significantly increased in response to sucrose feeding. Adipocytes were significantly larger in sucrosefed wild-type mice compared with sucrose-fed transgenic mice: $3623 \pm 88$ compared with $3236 \pm 93 \mu \mathrm{m}^{2}$ $(P<0.003$ by analysis of variance).

Expression of the transgene in cells derived from adipocytes was documented by Northern blotting using a cDNA probe that recognizes both the endogenous murine IGFBP-1 and rat IGFBP-1 derived from the transgene (Rajkumar et al. 1995). There was no expression of the endogenous gene in cultures derived from wild-type mice, whereas the rat IGFBP-1 mRNA, derived from the transgene, was easily detected in cultures derived from the transgenic mice (Fig. 3).

To determine whether the impaired adipogenic response to sucrose feeding in transgenic mice was the result of impaired proliferation or differentiation of adipocyte precursors, isolated cells derived from wild-type and transgenic fat tissue were allowed to adhere to tissue culture dishes for $24 \mathrm{~h}$ and the number of colonies 


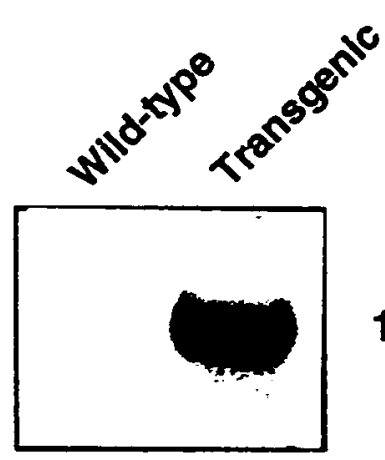

$1.5 \mathrm{~kb}$

GAPDH

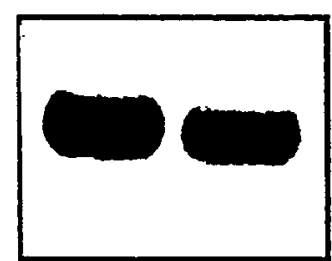

$1.3 \mathrm{~kb}$

Figure 3 Northern blot demonstrating expression of the transgene in cultures containing adipocyte precursors from wild-type and transgenic mice. Total RNA, $20 \mu \mathrm{g} /$ lane was analyzed.

Autoradiograms of the filter after hybridization with a radiolabeled IGFBP-1 (upper panel) and glyceraldehyde phosphate dehydrogenase (GAPDH, lower panel) cDNAs are shown.

determined after a further 3 days. These cultures include preadipocytes in addition to more immature adipocyte precursor cells. Significantly more colonies formed in dishes derived from wild-type mice compared with transgenic mice (Fig. 4). As only colonies of approximately 20 cells or more were scored, this assay reflects both the number of colony-forming cells and the proliferation of these cells into recognizable colonies. Colonies derived from transgenic mice were significantly smaller in area than those wild-type mice: $8 \cdot 26 \pm 2 \cdot 28 \times 10^{3}$ compared with $23 \cdot 31 \pm 4 \cdot 04 \times 10^{3} \mu \mathrm{m}^{2}(n=21, P<0 \cdot 005)$.

The mitogenic response to IGF-I and insulin was also examined in cultures containing adipocyte precursors from wild-type and transgenic mice (Fig. 5). Both IGF-I and insulin stimulated ${ }^{3} \mathrm{H}$-methyl-thymidine incorporation into DNA in these mixed cell cultures; IGF-I was more potent than insulin. There was no statistical difference between transgenic and wild-type preadipocytes in terms of the dose response for insulin. In contrast, IGF-I was significantly less potent $(P<0 \cdot 001$ by analysis of variance) in cultures from transgenic mice compared with wildtype mice. The addition of a 10-fold excess of human recombinant IGFBP-I to cultures from wild-type mice significantly attenuated the effect of IGF-I on ${ }^{3} \mathrm{H}$-methyl-thymidine incorporation into DNA (Fig. 5).

Differentiation of preadipocytes and other more immature adipocyte precursors into mature fat cells was assessed by measuring the induction of GPDH activity in

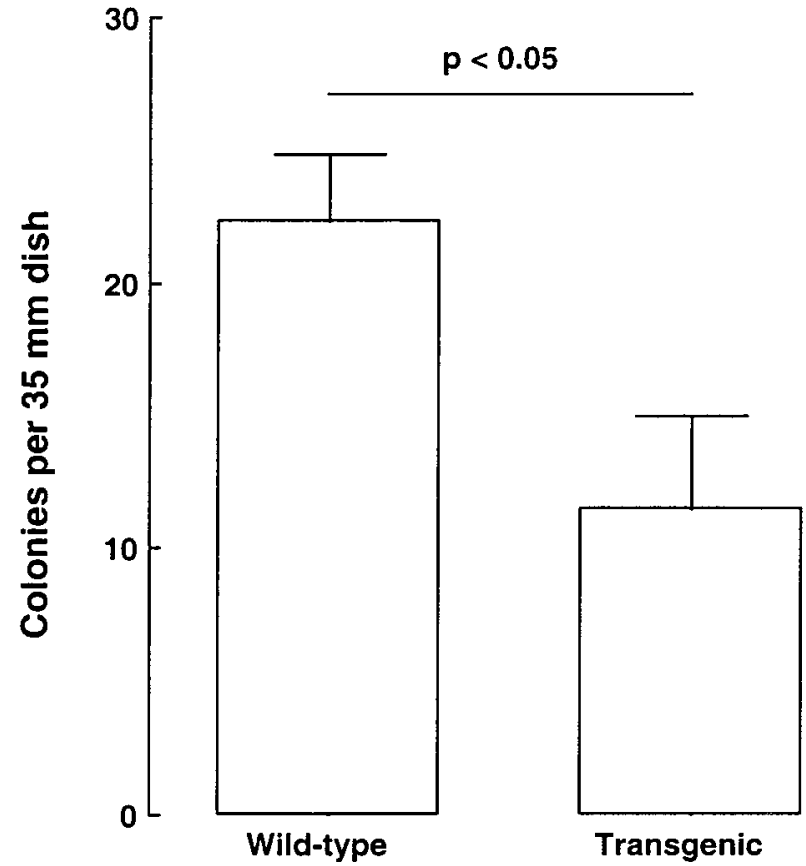

Figure 4 Colony formation in cultures containing adipocyte precursors from wild-type and transgenic mice. Cells were prepared from equivalent amounts of epididymal fat by collagenase and plated on tissue culture dishes. The data represent the means \pm S.E.M. for six animals per group.

confluent cultures and by scoring the percentage of cells that accumulated fat droplets. There was no significant difference in the basal GPDH activity in cultures from transgenic or wild-type mice (Fig. 6). Similarly, GPDH activity was not significantly different in insulin-treated cultures from transgenic and wild-type mice. The effect of IGF-I on differentiation, as measured by induction of GPDH activity, was significantly less than that seen with an equimolar amount of insulin and the action of IGF-I was significantly reduced in cultures from transgenic mice compared with wild-type mice (Fig. 6). Under basal conditions in the presence of 1\% charcoal-treated FCS, only approximately $10 \%$ of cells accumulated fat droplets (Fig. 7, Table 2). There was no significant difference between cultures from transgenic or wild-type mice. Morphological appearance was similar in cells derived from transgenic and wild-type mice. After 6 days in culture, in response to either IGF-I or 10\% FCS, approximately $40 \%$ of the cells differentiated into mature adipocytes as indicated by intracellular fat accumulation. There were significantly fewer cells containing fat droplets in cultures from transgenic mice treated with IGF-I as compared with wild-type cultures.

\section{Discussion}

The vast majority of the IGF-I and -II present in the circulation is bound to the IGFBPs, predominantly 


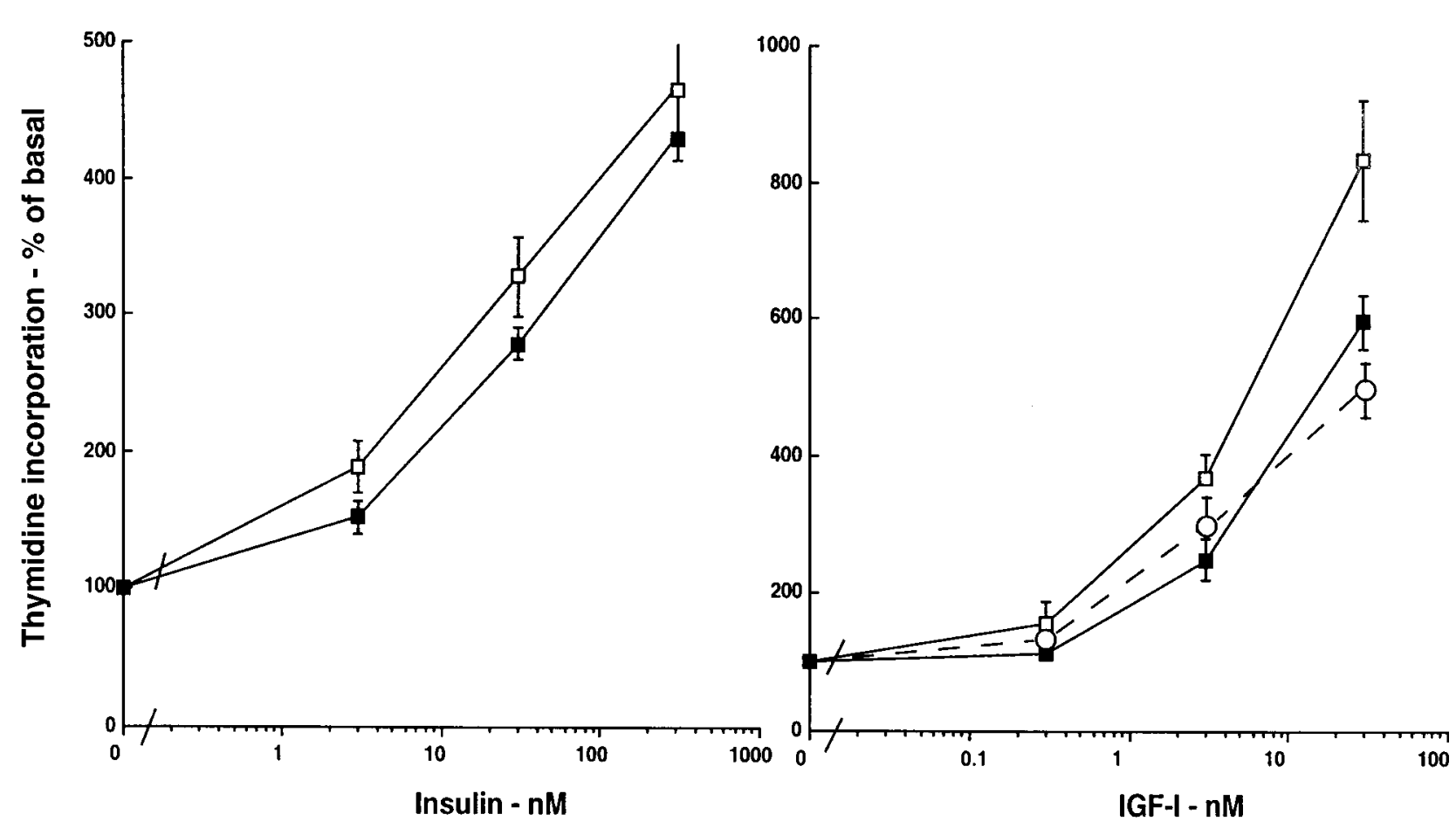

Figure 5 Effects of insulin and IGF-I on ${ }^{3} \mathrm{H}$-methyl thymidine incorporation into DNA in cell cultures containing adipocyte precursors from wild-type $(\square)$ and transgenic ( $\square$ ) mice. In the right panel, data are also shown for cell cultures from wild-type mice that were incubated with varying concentrations of IGF-I and 300 nM IGFBP-1 (O). The data represent the means \pm S.E.M. for cultures from six different mice per data point. The differences in the IGF-I responses for cell cultures from transgenic and wild-type mice and for cell cultures from wild-type mice incubated in the presence and absence of IGFBP-1 were statistically significant $(P<0 \cdot 001$ by analysis of variance).

IGFBP-3. However, overexpression of IGFBP-1 is accompanied by a reduction in growth, hyperglycemia and impaired cellular proliferation in response to a variety of stimuli (Rajkumar et al. 1995, 1996a, Ni et al. 1997). These observations appear to be manifestations of partial inhibition of IGF-I action. Here we have demonstrated that transgenic mice that overexpress IGFBP-1 also have a reduced ability to increase adipose mass in response to excess caloric intake. Despite comparable caloric intake, transgenic mice gained significantly less body weight and the increase in epididymal fat, a precisely measurable fat deposit, was markedly reduced compared with wild-type mice. This observation suggests that the transgenic mice expended more energy, absorbed less calories, or were less efficient at incorporating fat into adipose tissue. As no direct measures of calorie absorption or energy expenditure were made, it is not possible to determine whether transgenic and wild-type mice differ in these two parameters. However, the experiments reported here provide evidence that transgenic mice have fewer adipocyte precursors present in fat tissue, that these precursors proliferate more slowly, and that differentiation of these precursors into mature adipocytes is impaired.

Although the transgenic mice have impaired glucose tolerance after an i.p. glucose load (Rajkumar et al. 1995),

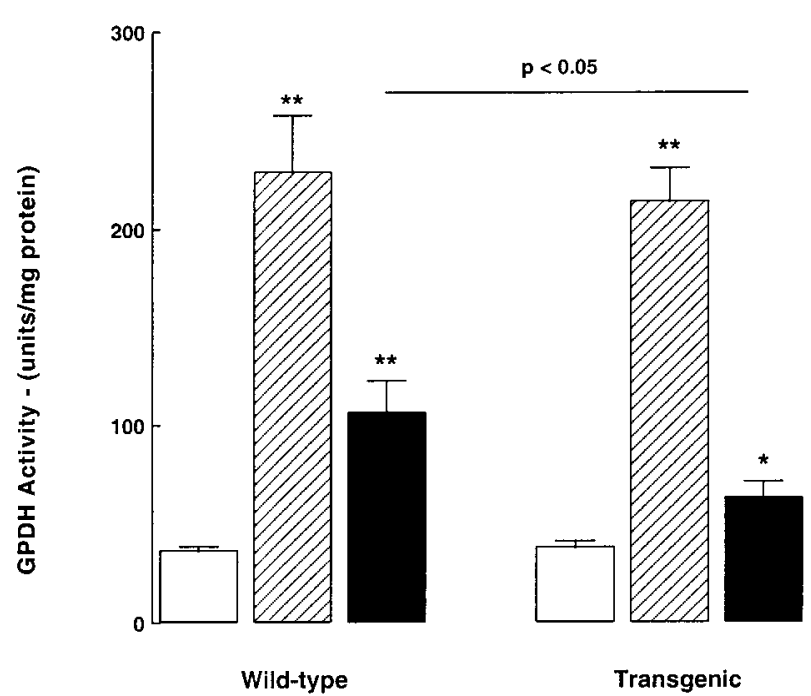

Figure 6 Effects of insulin and IGF-I on preadipocyte differentiation in transgenic and wild-type mice. The GPDH activity was measured under basal conditions (open columns) and after the addition of $10 \mathrm{nM}$ insulin (cross-hatched columns) or $10 \mathrm{nM}$ IGF-I (black columns). The data represent the means \pm S.E.M. for cultures from six different mice per group. ${ }^{\star} P<0 \cdot 05,{ }^{*} P<0 \cdot 001$ for the difference between treated and untreated basal cultures. The significant difference between the wild-type and transgenic mice is indicated. 


\section{Wild-Type}

\section{Transgenic}
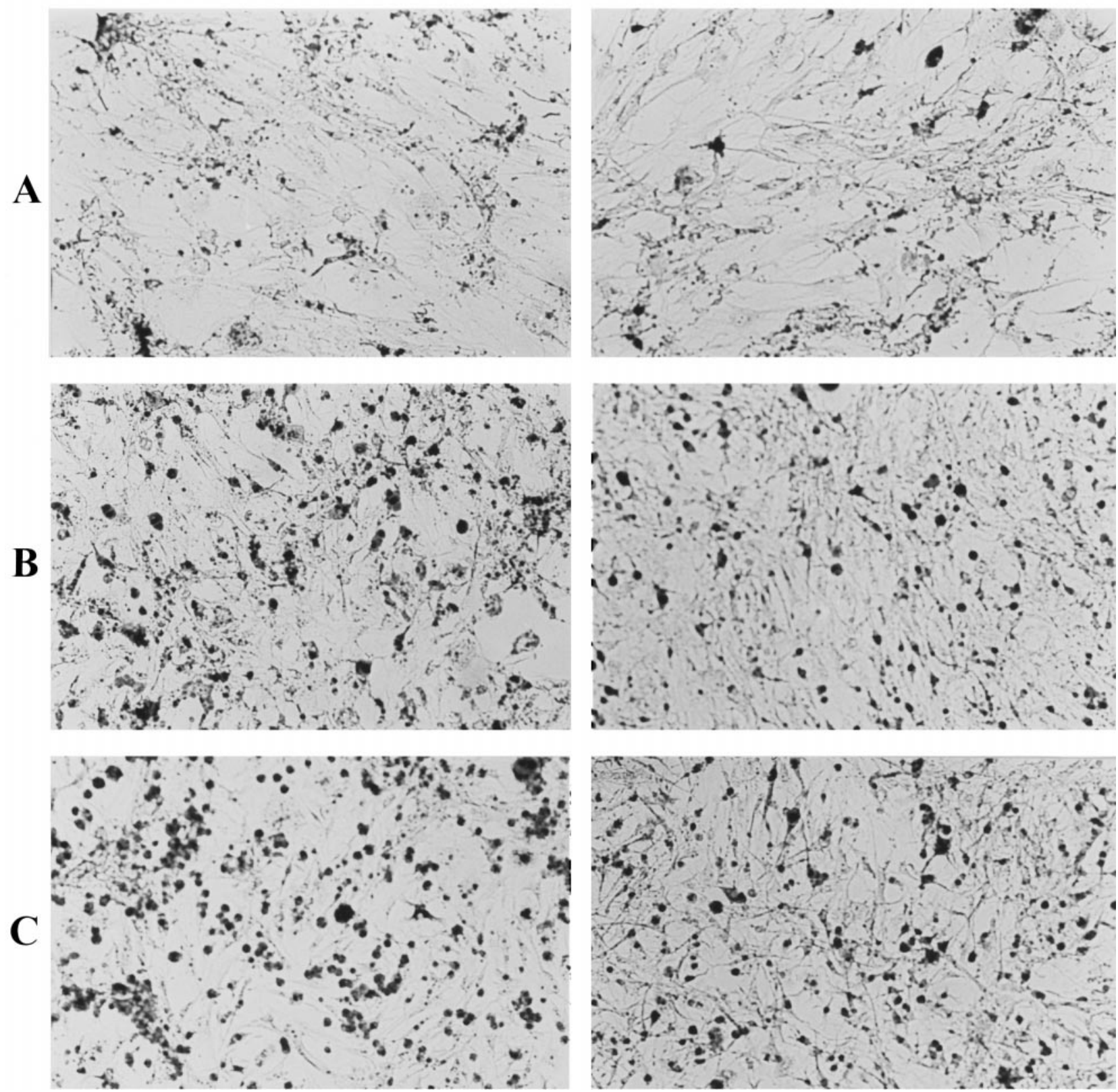

Figure 7 Effects of IGF-I and serum on intracellular fat accumulation. Cell cultures containing adipocyte precursors from wild-type and transgenic mice were grown for 6 days in medium containing 1\% charcoal-treated FCS (A), 1\% charcoal-treated FCS plus 100 nM IGF-I (B) or $10 \%$ FCS (C). Monolayers were stained with oil-red O to identify intracellular fat.

they are not frankly diabetic, and the difference in fat accumulation cannot be explained by urinary calorie loss. Water consumption, an indirect measure of urine production, was less in sucrose-fed transgenic mice compared with sucrose-fed wild-type mice. Furthermore, it is important to note that the relative weight of the epi- didymal fat pad was reduced in non-sucrose-fed transgenic mice, indicating that the defect was apparent even before the caloric challenge (Fig. 1).

The accumulation of adipose tissue is believed to involve commitment of stem cells to differentiate into adipoblasts, which undergo further differentiation into 
Table 2 Effects of IGF-I and serum on fat accumulation in preadipocytes from wild-type and transgenic mice. Cells derived from wild-type and transgenic fat tissue were cultured in the presence of $1 \%$ charcoal-treated FCS. The data (means \pm S.E.M.) represent the percentage of cells that accumulated fat droplets as determined by Oil-red $\mathrm{O}$ staining.

\begin{tabular}{|c|c|c|c|c|}
\hline & Wild-type & Transgenic & Numbert & Significance* \\
\hline Control (\%) & $7 \cdot 94 \pm 0.72$ & $10 \cdot 33 \pm 1 \cdot 60$ & 6 & $P=0.203$ \\
\hline IGF-I (100 nM) & $42.93 \pm 1.62$ & $31 \cdot 30 \pm 2 \cdot 91$ & 11 & $P=0.003$ \\
\hline $10 \%$ FCS & $42 \cdot 63 \pm 2 \cdot 51$ & $36 \cdot 29 \pm 2.06$ & 17 & $P=0.059$ \\
\hline
\end{tabular}

†Number of low power microscopic fields scored per dish; duplicate dishes were analyzed for each treatment group. *For the difference between transgenic and wild-type mice.

preadipocytes, young adipocytes and mature adipocytes (Doglio et al. 1987, Zezulak \& Green 1986, Nougues et al. 1993). This multistep process involves both differentiation and proliferation allowing clonal expansion of cells at each stage of the differentiation process. The failure of transgenic mice to accumulate adipose mass could result from a diminished initial stem cell population, reduced commitment and differentiation of adipocyte precursors, and attenuated proliferation of the partially differentiated cells at various stages. As the transgene is expressed at least as early at the blastocyst stage (Huang et al. 1996), the possibility of a reduced stem cell population exists. Indeed, IGF-I has been shown to inhibit apoptosis and enhance survival of many different cell types. Although it is possible to identify preadipocytes, the more immature adipocyte precursors are difficult to separate from other stromal cells present in adipose tissue. Here, we chose to use mixed cell cultures derived from fat tissue that contained all but the mature adipocytes, so that the various steps in the formation of adipose tissue could be examined. In addition to reduced numbers of colonies formed, which would reflect reduced numbers of immature stem cells and cells with high proliferative capability, the actual colony size was reduced in cultures derived from transgenic mice. This indicates that clonal expansion of these colony-forming cells derived from transgenic fat tissue is also impaired. This appears to be the result of inhibition of IGF-I action by the transgene-derived IGFBP-1, because exogenous IGF-I had a reduced mitogenic action in cell cultures derived from transgenic mice and recombinant IGFBP-1 reduced the mitogenic effect of IGF-I in cultures from wild-type mice.

In addition to the reduced proliferation or adipocyte precursors in fat tissue from transgenic mice, differentiation of adipocyte precursors was also impaired as determined by induction of GPDH activity and accumulation of intracellular fat. These latter determinations reflect the later stages in the adipocyte differentiation process, namely the transition of preadipocytes to mature adipocytes. Thus a number of factors appear to be important in the failure of the transgenic mice to accumulate adipose mass in response to excess caloric intake.

There was no significant difference in serum leptin concentrations between transgenic and wild-type mice fed normal chow, although epididymal fat mass was significantly less in transgenic mice. Serum leptin concentrations have been shown, in some studies, to correlate with the degree of adiposity (Considine et al. 1996); however, they also correlate with insulin concentrations (Considine et al. 1996). The greater insulin concentrations in the transgenic mice may compensate for the reduced fat mass in transgenic mice (Rajkumar et al. 1996b). Although, in both wild-type and transgenic mice, sucrose feeding resulted in an increase in serum leptin concentrations, only a small, non-significant increase in epididymal fat mass was seen in the transgenic mice. This observation suggests that there may be differences in the leptin adipocyte-hypothalamus feed-back loop in transgenic and wild-type mice. Further studies would be necessary to determine whether this is the case.

Under the culture conditions used here, IGF-I was more potent than insulin in stimulating proliferation of mouse adipocyte precursors whereas the opposite was true in regards to preadipocyte differentiation. Similar findings were observed in rat and sheep preadipocytes (Deslex et al. 1987, Vierck et al. 1996). In contrast, IGF-I appears to be more potent than insulin in inducing differentiation of 3T3-L1 cells (Smith et al. 1988). The differentiation of preadipocytes into adipocytes is accompanied by an increase in insulin receptors and a reduction in IGF-I receptors (Shimizu et al. 1986). This could explain, at least in part, the apparent differences in responsiveness of cells before and after differentiation.

Because insulin is more potent than IGF-I in inducing mouse preadipocyte differentiation, and circulating insulin concentrations are approximately threefold greater in transgenic mice (Rajkumar et al. 1996b), it is unlikely that the reduced accumulation of fat tissue in transgenic mice was the result of impaired preadipocyte differentiation alone. It is important to note that adipocytes from transgenic mice were not resistant to insulin when the effects of insulin on 2-deoxyglucose uptake (Rajkumar et al. 1996b) or the induction of GPDH activity (present study) were measured. Insulin resistance in the transgenic mice appears to be limited to skeletal muscle (Rajkumar et al. 1996b).

Growth hormone has also been shown to be important in preadipocyte proliferation and differentiation. In 3T3-L1 cells, growth hormone is necessary for IGF-I- 
induced proliferation and differentiation (Zezulak \& Green 1986). In preadipocytes from various species, the effects of growth hormone on adipocyte differentiation is less marked (Sypniewska et al. 1987, Wiederer \& Loffler 1987). Indeed, in human preadipocytes, growth hormone appears to inhibit differentiation but stimulates proliferation (Wabitsch et al. 1996). In adult transgenic mice, basal serum growth hormone concentrations are similar to those in wild-type mice (unpublished observations). Thus it is unlikely that growth hormone deficiency would be the explanation for reduced adipose mass in the sucrose-fed transgenic mice. Although not specifically the subject of the experiments reported here, the observation that the sucrose-fed transgenic mice gained less weight than the sucrose-fed wild-type mice, despite similar calorie intake, requires further investigation. A detailed examination of carcass composition, together with a precise measure of calorie absorption and energy expenditure are required before any conclusions can be reached concerning the relative efficiencies of the transgenic and wild-type mice in calorie utilization. In addition, further studies of relative proportions of white and brown adipose tissue and the relative expression of uncoupling enzymes in the transgenic and wild-type mice are warranted.

The observation that inhibition of IGF-I action is associated with impaired accumulation of adipose tissue is of potential clinical relevance. IGF-I receptor antagonists or agents that specifically inhibit IGF-I signal transduction in adipocytes may be of potential therapeutic use in the treatment of obesity, particularly in individuals with genetic predisposition identified early in life.

\section{Acknowledgements}

This research was supported by a grant from the Canadian Diabetes Association in honor of Edward C Cornes, and by the Medical Research Council of Canada. LJ M is a recipient of an endowed Research Professorship in metabolic diseases.

\section{References}

Chomczynski P \& Sacchi N 1987 Single-step method of RNA isolation by acid guanidium thiocyanate-phenol-chloroform extraction. Analytical Biochemistry 162 156-159.

Considine RV, Sinha MK, Heiman ML, Kriauciunas A, Stephens TW, Nyce MR, Ohannesian JP, Marco CC, McKee LJ, Bauer TL \& Caro JF 1996 Serum immunoreactive leptin concentrations in normal-weight and obese humans. New England Journal of Medicine 334 292-295.

Deslex S, Negrel R \& Ailhaud G 1987 Development of a chemically defined serum-free medium for differentiation of rat adipose precursor cells. Experimental Cell Research 168 15-30.

Doglio A, Dani C, Fredrikson G, Grimaldi P \& Ailhaud G 1987 Acute regulation of insulin-like growth factor-I gene expression by growth hormone during adipose cell differentiation. EMBO Journal 6 4011-4016.
Gaskins HR, Kim JW, Wright JT, Rund LA \& Hausman GJ 1990 Regulation of insulin-like growth factor-I ribonucleic acid expression, polypeptide secretion and binding protein activity by growth hormone in porcine preadipocyte cultures. Endocrinology 126 622-630.

Huang H, Rajkumar K \& Murphy LJ 1996 Reduced fecundity in insulin-like growth factor binding protein-1 transgenic mice. Biology of Reproduction 56 284-290.

Murphy LJ, Seneviratne C, Ballejo G, Croze F \& Kennedy T 1990 Identification and characterization of a rat decidual insulin-like growth factor binding protein cDNA. Molecular Endocrinology 4 329-337.

Ni W, Rajkumar K, Nagy J \& Murphy LJ 1997 Impaired brain development and reduced reactive astrocyte response to injury in insulin-like growth factor binding protein-1 transgenic mice. Brain Research 769 97-107.

Nougues J, Reyne Y, Barenton B, Chery T, Garandel V \& Soriano J 1993 Differentiation of adipocyte precursors in a serum-free medium is influenced by glucocorticoids and endogenously produced insulin-like growth factor-I. International Journal of Obesity 17 159-167.

Rajkumar K, Barron D, Lewitt MS \& Murphy LJ 1995 Growth retardation and hyperglycemia in insulin-like growth factor binding protein-1 transgenic mice. Endocrinology 136 4029-4034.

Rajkumar K, Dheen ST, Krsek M \& Murphy LJ 1996a Impaired estrogen action in the uterus of insulin-like growth factor binding protein-1 transgenic mice. Endocrinology 137 1258-1264.

Rajkumar K, Krsek M, Dheen ST \& Murphy LJ $1996 b$ Impaired glucose homeostasis in insulin-like growth factor binding protein-1 transgenic mice. Journal of Clinical Investigation 98 1818-1825.

Rechler MM 1993 Insulin-like growth factor binding proteins. Vitamins and Hormones 47 1-114.

Shimizu M, Torti F \& Roth RA 1986 Characterization of the insulin and insulin-like growth factor receptors and responsitivity of a fibroblast/adipocyte cell line before and after differentiation. Biochemical Biophysical Research Communications 137 552-558.

Smith PJ, Wise LS, Berkowitz R, Wan C \& Rubin CS 1988 Insulin-like growth factor-I is an essential regulator of the differentiation of 3T3-L1 adipocytes. Journal of Biological Chemistry 263 9402-9408.

Sypniewska G, Xu X, Hager A, Lindahl A \& Bjorntorp P 1987 Effects of age, obesity and human growth-hormone on adipogenic activity in human plasma. International Journal of Obesity $\mathbf{1 1}$ 263-273.

Wabitsch M, Braun S, Hauner H, Heinze E, Ilondo MM, Shymko R, de Meyts P \& Teller WM 1996 Mitogenic and antiadipogenic properties of human growth hormone in differentiating adipocyte precursor cells in primary culture. Pediatric Research 40 450-456.

Wiederer O \& Loffler G 1987 Hormonal regulation of the differentiation of rat adipocyte precursor cells in primary culture. Journal of Lipid Research 28 649-658.

Wise LS \& Green H 1979 Participation of one isozyme of cytosolicglycerophosphate dehydrogenase in the adipose conversion of 3T3 cells. Journal of Biological Chemistry 254 273-275.

Vierck JL, McNamara JP \& Dodson MV 1996 Proliferation and differentiation of progeny of ovine unilobular fat cells (adipofibroblasts). In Vitro Cell and Developmental Biology 32 564-572.

Zezulak KM \& Green H 1986 The generation of insulin-like growth factor-I sensitive cells by growth hormone action. Science $\mathbf{2 3 3}$ $551-553$.

Received 16 September 1998

Revised manuscript received 25 March 1999 Accepted 9 April 1999 